\title{
A individualização dos percursos formativos como princípio organizador das políticas curriculares para o Ensino Médio no Brasil
}

Roberto Rafael Dias da Silva ${ }^{a}$

\section{Resumo}

O presente artigo propõe-se a examinar os modos pelos quais a individualização dos percursos formativos é posicionada enquanto um princípio organizador das políticas curriculares para o Ensino Médio implementadas no Brasil, ao longo desta década. Ao inscrever-se no campo dos Estudos Curriculares, descreve e analisa como a escolarização juvenil passa a ser redimensionada no âmbito de diferentes "surtos individualizatórios", intensificados nas condições de uma "economização da vida social" e da visibilização dos paradoxos de uma "crise do Estado". Realiza uma análise de políticas curriculares mobilizadas nos estados do Rio Grande do Sul, de Minas Gerais e do Rio de Janeiro.

Palavras-chave: Políticas curriculares. Ensino Médio. Individualização. Brasil.

Ao mesmo tempo em que mergulha na irrelevância, ele é elevado a um trono fictício de reformador do mundo (BECK, 2010, p. 202).

Tornou-se recorrente, na implementação de políticas curriculares contemporâneas destinadas aos variados níveis de ensino em inúmeros países, a centralidade de práticas de individualização dos percursos formativos. Noções como personalização, customização e diferenciação passaram a operar, enquanto dispositivos curriculares que estruturam a formação humana, a partir das escolhas, dos interesses e das necessidades dos indivíduos (BALL, 2016; LAVAL, 2004; SILVA, 2016a). Tomando como material empírico um conjunto de incursões investigativas em variados regimes de implementação de políticas curriculares para o Ensino Médio, engendradas no Brasil ao longo da última década, mobilizaremos nossa

a Universidade do Vale do Rio dos Sinos, São Leopoldo, RS, Brasil. 
argumentação para descrever e analisar os modos pelos quais a escolarização juvenil passa a ser redimensionada no âmbito de diferentes "surtos individualizatórios" (BECK, 2010), intensificados nas condições de uma "economização da vida social" (PETERS, 2016) e da visibilização dos paradoxos de uma "crise do Estado" (BAUMAN, 2016).

Ancorados no campo dos Estudos Curriculares e valendo-nos de reflexões críticas advindas das teorizações sociais contemporâneas, no presente texto consideraremos a mobilização conceitual de três noções centrais nas políticas examinadas, quais sejam: a) as "áreas de empregabilidade", implementadas na reforma curricular de Minas Gerais, no período entre os anos de 2010 e 2014; b) as "competências socioemocionais", derivadas das reformulações desenvolvidas no Estado do Rio de Janeiro em parceria com o Instituto Ayrton Senna; c) as "comunidades de aprendentes”, organizadas na forma de seminários integrados, consideradas enquanto princípio basilar da política de Ensino Médio implementada no Rio Grande do Sul, no período entre 2010 e 2014. A partir da articulação produtiva entre determinadas racionalidades políticas, articuladas a variados regimes de práticas, constatamos a configuração de um dispositivo de diferenciação curricular que atribui centralidade a certos formatos escolares centrados nas possibilidades de escolha dos jovens na escola contemporânea. Em outras palavras, argumentaremos que a diferenciação curricular para essa etapa da educação básica é desenvolvida através de variados dispositivos de individualização.

Em sociedades neoliberais, a governança institucional atribui centralidade para a constituição de um novo tipo de indivíduo (BALL, 2016). As mudanças na organização do Estado, nas últimas décadas, favoreceram o engendramento de diferentes tipos de atores e trabalhadores no campo educativo. "O neoliberalismo se plasma em um 'novo tipo de indivíduo', um indivíduo formado na lógica da competição: um 'homem empresarial' - calculista, solipsista e instrumentalmente dirigido" (BALL, 2016, p. 30). De acordo com Laval (2004), em perspectiva sociológica, o cenário que permite a multiplicação dos dispositivos de individualização associa-se também a uma mudança do próprio estatuto do conhecimento. $\mathrm{O}$ conhecimento, então, torna-se produto de "um investimento mais ou menos rentável em indivíduos desigualmente dotados e capacitados" (p. 57).

Cumpre reiterar, todavia, a perspectiva de que o Ensino Médio no Brasil recebeu inúmeras e variadas reformas curriculares ao longo das últimas décadas (KRAWCZYK, 2011; SILVA; JAKIMIU, 2016). Atendendo a racionalidades políticas heterogêneas, tais reformas têm sido engendradas através de múltiplos sistemas de raciocínio pedagógico que, atualmente, direcionam-se para o 
atendimento das demandas econômicas, dos interesses juvenis e das possibilidades de proteção social (KRAWCZYK, 2014; SILVA, 2016a). Em consonância com esse cenário, conforme sinalizamos anteriormente, no presente artigo pretendemos examinar os modos pelos quais as políticas curriculares implementadas em distintas regiões brasileiras, no decorrer desta década, têm sido reguladas por variados modelos de individualização dos percursos formativos ancorados nas noções de empregabilidade, competências socioemocionais e comunidades de aprendentes. A escolha por estes contextos investigativos deve-se à sua potencialidade pedagógica e aos seus modos de difusão de princípios curriculares na literatura brasileira sobre a questão. Organizaremos o presente texto em três seções, quais sejam: a) uma retomada do conceito de diferenciação curricular; b) um diagnóstico sociológico acerca da individualização; c) um conjunto de análises das políticas curriculares acima evidenciadas, atribuindo ênfase analítica para a individualização dos percursos formativos enquanto princípio orientador das políticas curriculares para o Ensino Médio, no Brasil contemporâneo.

\section{Sobre a diferenciação curricular no Ensino Médio: uma problematização}

Os debates acerca da diferenciação curricular para os níveis equivalentes ao Ensino Médio não constituem uma novidade na literatura educacional. Estudos como os de Hart (1996) ou de Perrenoud (2000), no final do século XX, sinalizavam para uma intrínseca correlação entre diferenciação e igualdade de oportunidades. Questões como a integração curricular, o trabalho em pequenos grupos de aprendizagem (FAWTHROP, 1996), a preocupação com os estilos de aprendizagem, (FIELDING, 1996) ou mesmo a ênfase em práticas pedagógicas inovadoras, tornaram-se recorrentes nos estudos que focalizavam a escolarização dos jovens. Em comum a essas preocupações, encontramos na formulação de Perrenoud (2000), por exemplo, a perspectiva de que "o verdadeiro desafio é imaginar dispositivos que favoreçam interações entre alunos, no âmbito de diversos grupos de trabalho, sem impedir uma individualização da trajetória de cada um" (p. 12). De forma geral, poderíamos afirmar que a diferenciação curricular é apresentada como uma questão emblemática para a escolarização juvenil na Contemporaneidade.

Em diálogo com a literatura luso-brasileira, poderíamos tomar como ponto de partida, para examinar a diferenciação curricular, o entendimento "do currículo como um plano diferenciado", que se baseia "na necessidade de adaptar e flexibilizar o que é comum, geralmente o que é componente nacional, a todos os alunos e realidades contextuais" (PACHECO, 2014, p. 70). Considerando a forma escolar engendrada pela Modernidade, na qual seria privilegiado um modelo 
hierarquizante e monocultural - no que tange ao acesso aos saberes escolares as pedagogias do século XX assumiram a diferenciação curricular enquanto um princípio pedagógico basilar. Exemplar, nessa direção, seria a "escola sob medida" proposta pela teorização do psicólogo Claparède (1973), na primeira metade do século passado ${ }^{1}$.

A promoção da igualdade de oportunidades, através de políticas curriculares centradas na equidade, encaminhou-se para a necessidade de mobilizar outros arranjos curriculares. Sousa (2010), em sua abordagem, afirma que a "diferenciação curricular tem sido cada vez mais perspectivada como uma resposta que urge dar à crescente diversidade estudantil que caracteriza a escola contemporânea" (p. 17). Em tais condições argumentativas, as teorizações curriculares da virada do século atribuíram centralidade para as noções de diversidade, diferença, inclusão, equidade, identidade, reconhecimento e pluralidade.

Diferenciar o currículo pode ser caracterizado como um imperativo político das escolas de nosso tempo; todavia tal imperativo é posicionado e implementado a partir de lógicas políticas diferenciadas. De acordo com Sousa (2010), a lógica de implementação da diferenciação curricular pode dar-se em diferentes âmbitos ou esferas políticas, operando tanto no nível macro, quanto no nível micro. Importa enfatizar ainda que, para além dessa variação nos âmbitos de intervenção, reconhecemos relevância em mapear as variadas estratégias políticas colocadas em ação. Por exemplo, a partir de uma concepção inclusiva, Sousa (2010) entende por diferenciação curricular "a adaptação do currículo às características de cada aluno, com a finalidade de maximizar as suas oportunidades de sucesso escolar" (p. 10). Ainda de acordo com Sousa, parece haver uma permanente tensão entre as diferentes tendências que conceituam a diferenciação, do ponto de vista teórico.

$\mathrm{Na}$ literatura latino-americana sobre o Ensino Médio, também encontramos uma acentuada preocupação com a promoção de formatos curriculares alternativos. Junto ao declínio da institucionalidade da escola moderna, Tiramonti (2014) defende que hodiernamente "é necessário avançar na construção de um âmbito escolar capaz de fazer do heterogêneo o elemento vertebrador da prática escolar" (p. 33). Da mesma forma, ao comentar seus estudos sobre a experiência de diferenciação curricular das Escolas de Reingresso, desenvolvidas em Buenos Aires, Nobile (2016) argumenta sobre o caráter ambivalente de políticas dessa natureza. "Assim como podem oferecer novas oportunidades às populações vulneráveis, também

\footnotetext{
Na lógica da argumentação claparediana, um dos primeiros aspectos a serem reconhecidos seriam as capacidades naturais dos estudantes. Para produzir uma educação que atenda às variações individuais, era necessário reconhecer que "um indivíduo só produz na medida em que se apela para suas capacidades naturais, e que é perder tempo querer por força desenvolver nele capacidades não-possuídas" (Claparède, 1973, p. 174).
} 
podem gerar novas desigualdades ao exigir que os sujeitos criem um relato de suas vidas, que se façam responsáveis por suas trajetórias e que as afrontem a partir das 'ferramentas' com que estas políticas de individualização lhes brindam" (NOBILE, 2016, p. 188-189).

Ao reconhecermos a pertinência e a atualidade da literatura revisada nesta seção, sinalizamos para a variedade de finalidades pedagógicas e de estratégias políticas que podem orientar a diferenciação curricular. Acerca do Ensino Médio, no Brasil, nossa ênfase analítica, então, ancora-se na perspectiva de que sua orientação é derivada da individualização dos percursos formativos associada a uma economização da vida social. Como podemos compreender a centralidade atribuída à diferenciação curricular para o Ensino Médio ao longo da última década? Os processos de diferenciação ocorrem em sintonia com o declínio do Estado e de suas funções públicas? Ainda conseguimos planejar o desenvolvimento de uma política curricular que atenda às diferenças individuais sem desvalorizar a composição de uma pauta formativa comum para os jovens contemporâneos?

\section{Diagnóstico sobre a individualização: uma perspectiva sociológica}

Considerando que as políticas contemporâneas sinalizam para uma centralidade da individualização, enquanto forma explicativa da vida social de nosso tempo, o sociólogo Beck (2010) explica-nos que as situações e estilos de vida individualizados não foram inventados na segunda metade do século XX. Antes disso, a individualização perfaz a própria constituição da Modernidade $^{2}$, acompanhando, inclusive, "determinados aspectos subjetivo-biográficos do processo civilizatório (no sentido de N. Elias), em especial em seu último grau, na industrialização e na modernização" (BECK, 2010, p. 190). Valendo-se da situação da Alemanha, no final do século XX, em sua obra "Sociedade de risco", o sociólogo descreve a configuração de um "surto individualizatório", derivado da própria dissolução das classes sociais, bem como de mudanças derivadas do âmbito da cultura e da produção econômica.

Ao explicar tal "surto individualizatório", Beck explora pelo menos três teses gerais que nos permitiriam explorar heuristicamente este processo. O primeiro aspecto teórico descrito pelo autor refere-se ao declínio das classes sociais enquanto princípio explicativo da vida coletiva, cenário no qual "o próprio indivíduo se

\footnotetext{
2 Os debates acerca das tensões existentes entre individualização e formação de classe não se constituíram em uma temática recorrente na sociologia clássica. Todavia, pensadores como Karl Marx e Max Weber, de forma diferenciada, chegaram a tematizar aspectos concernentes à individualização burguesa ou mesmo sobre a individualização pelo mercado de trabalho (BECK, 2010).
} 
converte em unidade reprodutiva do social no mundo vital" (BECK, 2010, p. 193). A segunda tese diz respeito aos modos pelos quais os processos que geram a individualização também engendram mecanismos de padronização. Em suas palavras, "isto vale, sempre de maneiras distintas, para o mercado, o dinheiro, a mobilidade, a educação, etc. As situações individuais assim produzidas são inteiramente dependentes do mercado (de trabalho)" (BECK, 2010, p. 193). A terceira tese associa-se ao entendimento de que a individualização atravessa a esfera privada, da mesma forma que os variados espaços públicos.

Com o declínio dos tradicionais vínculos de classe, podemos constatar "um processo de individualização e diversificação de situações e estilos de vida que ilude o modelo hierárquico das classes e estratos e suspende-o no que diz respeito à sua efetividade" (BECK, 2010, p. 114). São variados os componentes que explicam esse impulso individualizatório ${ }^{3}$, dentre os quais poderíamos destacar a mobilidade, entendida nos planos social, geográfico ou mesmo cotidiano. Considerando estilos de vida e de consumo desiguais e as ressignificações das identificações coletivas, ainda conforme Beck, engendrariam condições para uma "relativização dos modos de vida tradicionais". Em suas palavras, "os caminhos que as pessoas seguem na vida se autonomizam, em relação às condições e aos vínculos a partir dos quais elas surgiram ou sob os quais acabaram de ingressar" (BECK, 2010, p. 117).

Os variados "surtos individualizatórios", intensificados contemporaneamente, também podem auxiliar-nos a examinar analiticamente as atuais formas de apresentação e administração da pobreza. Utilizando-se de diagnósticos sobre seu país, Beck (2010) expõe que "a individualização não contradiz, pelo contrário, explica a peculiaridade dessa "nova pobreza"" (BECK, 2010, p. 134). Em outras palavras, a pobreza passa a ser lida em termos de destino individual. "Os afetados têm de arcar por conta própria com algo para o que a experiência da pobreza e os contextos da vida definidos pela classe ofereciam e manejavam contra interpretações de consolo e formas de defesa e apoio" (BECK, 2010, p. 134).

Tomando a pobreza ou o desemprego enquanto exemplares analíticos, a argumentação sociológica de Beck leva-nos a considerar que "a unidade referencial atingida pelo raio do desemprego e da pobreza já não é o grupo, a classe ou a camada social, mas o indivíduo de mercado em suas circunstâncias específicas" (p. 134). Como decorrência dessa questão, poderíamos descrever brevemente as novas formas de considerar o fracasso pessoal (que o sociólogo nomeia como

\footnotetext{
3 De perspectivas teóricas diferenciadas, pensadores sociais como Gilles Lipovetsky, Manuel Castells e Alan Touraine também consideraram analiticamente a questão da individualização na Modernidade.
} 
"via crucis da autoconfiança") ou também a reconstrução estatística da realidade social. Importa ainda considerar o próprio declínio das políticas advindas do Estado de Bem-Estar Social, os diagnósticos de "compartilhamento de risco" e também a precarização das condições existenciais.

Além do desemprego e da pobreza, outra nuance particular dos surtos individualizatórios, descritos por Beck (2010), diz em respeito ao "desdobramento da vida privada" ( $\mathrm{p}$. 144). De forma ambivalente, a partir dos anos 1950 , adquiriram contornos específicos os processos de autoconfiguração das condições existenciais, hibridizando, inclusive, as fronteiras entre os espaços públicos e os espaços privados. De acordo com o sociólogo, a realização pessoal - a busca por vida plena e feliz - torna-se um imperativo de vida, ultrapassando símbolos tradicionais do mundo do trabalho como carreira, status ou condições salariais. Beck (2010) sugere que "a consequência é que as pessoas acabam, de forma cada vez mais gritante, caindo no labirinto do autodesconcerto, da autoindagação e da autoasserção" (p. 145). A individualização, então, delinearia a emergência de um conjunto de novos especialistas, tendências, roteiros, indústrias, dispositivos e religiões. O sociólogo assinala a configuração de uma nova ética, capaz de ser ativada "com as próprias mãos".

O contexto de proliferação de "surtos individualizatórios", descritos por Beck (2010), intensificou-se nas condições de uma "crise do Estado" (BAUMAN, 2016). De acordo com Bauman, em recente elaboração, poderíamos afirmar que "a crise enfrentada pelo mundo ocidental não é temporária, mas sinal de uma mudança profunda que envolve todo o sistema social e econômico e que terá efeitos de longa duração" (2016, p. 7). Na medida em que o Estado foi redimensionado, não mais dispondo de meios e recursos efetivos para a regulação pública, adquire força um conjunto de redes e fluxos ("politicamente incontroláveis") que operam além de suas próprias fronteiras. Em um exercício de síntese, o sociólogo polonês diagnostica duas questões derivadas desse cenário, a saber: a) o déficit de poder da política; b) a desintegração do Estado-nação ${ }^{4}$.

A crise do Estado, associada à emergência de saberes da nova administração, permitiu com que suas funções fossem "deslocadas ('transferidas', 'terceirizadas' e/ou 'contratadas') para o mercado, esse espaço reconhecidamente 'sem política'; ou deixadas sobre os ombros de indivíduos humanos [...]” (BAUMAN, 2016, p. 19). Assim sendo, as próprias peculiaridades individuais adquirem valor agregado, na medida em que a individualização se torna a estratégia política privilegiada. $\mathrm{Na}$ acepção do sociólogo, "na economia e no Estado, assim como na política da vida no cenário líquido moderno, a individualidade substitui a ordem, e a

${ }_{4}^{4}$ Acerca da crise do Estado, importa demarcar as contribuições de Balibar (2012) e Jessop (2006). 
individualização demite a ordenação da agenda dos objetivos mais elevados e da lista de interesses supremos" (BAUMAN, 2016, p. 68).

A centralidade da individualização, descrita sociologicamente por Beck e Bauman, favorece a emergência e a consolidação de uma "economização da vida social" (FUMAGALLI, 2016; PETERS, 2016). Por um lado, importa assinalar que a própria aprendizagem está diretamente vinculada "à subjetividade, expertise e individualidade do trabalhador" (FUMAGALLI, 2016, p. 16). Por outro lado, vê-se a "evolução dos tipos de contrato de trabalho na direção de uma condição de precariedade estrutural, existencial e generalizada" (p. 17). Individualização e precarização, associadas a uma financeirização da vida, favorecem a instauração de novas formas de governança subjetiva.

De acordo com Fumagalli (2016), essa nova governança opera tanto no âmbito do controle sobre a produção de conhecimento, quanto na criação de um "imaginário individualista". Seus modos de operação, sobretudo nas reformas educacionais, lançam mão do "dispositivo do mérito e da recompensa individual e seletiva" (FUMAGALLI, 2016, p. 18). Nas palavras do economista, "o objetivo é transformar a individualidade diferente (tornada trabalho e valor) em subjetividade individualista, perpetuamente em competição, que depois se autodesvanece" (p. 18).

Na medida em que podemos constatar uma crise do Estado (BAUMAN, 2016), coadunada com a intensificação dos "surtos individualizatórios" (BECK, 2010), os modos de operação das políticas educacionais contemporâneas vinculam-se aos recursos do mérito e da recompensa individual (FUMAGALLI, 2016). No âmbito das políticas curriculares para o Ensino Médio, no Brasil, este cenário adquire nuances específicas, sobretudo ao fabricar diferenciação curricular através de dispositivos de individualização. Para apresentar essa hipótese investigativa, a seguir exploraremos políticas com foco nessa etapa da Educação Básica, implementadas no decorrer desta década nos Estados do Rio de Janeiro, de Minas Gerais e do Rio Grande do Sul.

\section{A individualização dos percursos como princípio organizador}

Buscando uma primeira aproximação aos materiais empíricos selecionados, vale a pena retomar a consolidação dos dispositivos de individualização no contexto do neoliberalismo contemporâneo 5 . De acordo com Ball (2016), o neoliberalismo "se

\footnotetext{
Importa salientar que, do ponto de vista metodológico, realizamos a coleta, leitura e análise documental dos principais textos orientadores das políticas curriculares que compõem o corpus empírico selecionado para este estudo.
} 
plasma em relações práticas de competição e exploração nos negócios, mas também, cada vez mais, em formas muito correntes e imediatas em nossas instituições da vida cotidiana e, assim, "nos faz"” (p. 30). Sob inspiração do pensamento foucaultiano do final da década de 1970, o pesquisador destaca que, para além de um regime econômico ou um sistema político, o neoliberalismo instaura modos de vida. "Em seu aspecto mais visceral e íntimo, o neoliberalismo implica a transformação de nossas relações e práticas sociais em cálculos e intercâmbios" (BALL, 2016, p. 30). Emergem determinadas formas de investimento econômico sobre os indivíduos, em geral, e sobre as políticas educativas, em particular, engendrando novas técnicas de regulação (e autorregulação) que promovem a competitividade.

A concorrência e os modos empresariais de organização da vida operam, então, para além do campo econômico. Privilegiam-se esses aspectos em variados setores da vida, inclusive ingressando nas pautas da escolarização de nosso tempo. Conforme Dardot e Laval (2016), "a exigência de 'competitividade' tornou-se um princípio político geral que comanda as reformas em todos os domínios, mesmo os mais distantes dos enfrentamentos comerciais no mercado mundial" (p. 27). Sob tais condições, argumentaremos nessa seção, através da análise de três políticas curriculares recentemente implementadas no Brasil, que os processos de diferenciação curricular tomam a individualização dos percursos como seu princípio organizador. A ênfase na empregabilidade, nas competências socioemocionais e nas comunidades de aprendizagem, com suas estratégias peculiares, colocam em ação determinados dispositivos de individualização, em sintonia com as tramas sociais e políticas engendradas contemporaneamente.

\subsection{A empregabilidade como princípio curricular}

O programa Reinventando o Ensino Médio foi desenvolvido pelo Estado de Minas Gerais, na gestão 2011-2014, e trazia como proposta central, do ponto de vista curricular, uma preocupação com as novas demandas educacionais derivadas do contexto da nomeada sociedade do conhecimento. As pressões advindas dos novos arranjos culturais, bem como das questões atinentes ao desenvolvimento econômico, foram vinculadas no documento orientador da referida proposta curricular para o Ensino Médio ao "fator conhecimento". A preocupação com este fator, mais do que uma problemática epistemológica, é situada sob outras configurações pedagógicas. Na justificativa do documento, defendia-se que "o campo do acesso ao conhecimento é onde, no nosso tempo, está sendo decidido o futuro das nações e, considerada uma sociedade em particular, é onde está sendo decidido o futuro dos seus cidadãos" (MINAS GERAIS, 2011, p. 5). A preocupação evidenciada com o "fator conhecimento" 
posicionava-se no âmbito de uma prosperidade econômica das nações e de cada um de seus indivíduos.

Para o atendimento a essa questão, é proposta uma articulação entre as questões da educação, da empregabilidade e da cidadania, considerada enquanto "uma exigência a ser cumprida por quaisquer políticas educacionais compatíveis com a contemporaneidade" (p. 6). Esta proposição curricular é defendida em seus textos orientadores enquanto uma estratégia de gestão, de caráter proativo, que indicava "uma preocupação em desenvolver um Ensino Médio consentâneo com o nosso tempo e, de outro lado, trata-se de buscar formas de enfrentar problemas que, apesar de virem de longa data, permanecem cruciais" (p. 6). Em outras palavras, a proposta de Minas Gerais assumia como base para sua reformulação as questões da identidade, da empregabilidade e da qualificação acadêmica. Despertou nossa atenção, para fins dessa analítica, o posicionamento da empregabilidade enquanto princípio curricular ${ }^{6}$, exploraremos a seguir alguns de seus delineamentos.

A empregabilidade, enquanto um princípio curricular, não estava vinculada à fabricação de currículos profissionalizantes, que eventualmente atendessem a demandas imediatas, provenientes dos mercados empregadores. Entendiase por empregabilidade, no âmbito da proposta Reinventando o Ensino Médio, "a oferta de uma formação que possibilite ao estudante dispor de maiores condições de inserção múltipla no mercado de trabalho" (MINAS GERAIS, 2011, p. 8). Como estruturante daqueles currículos escolares, foi organizado um acervo de áreas de empregabilidade, a serem ofertadas de acordo com os perfis da escola e da comunidade regional. Todavia, importa destacar que a seleção das áreas de empregabilidade seria derivada da escolha das próprias instituições escolares e, particularmente, aos estudantes compreendidos enquanto "autores do seu percurso curricular" (p. 8). A opção pela empregabilidade, enquanto princípio curricular, associada aos processos de escolha dos estudantes, era justificada pelo seu potencial de ampliação da competitividade dos jovens ao acesso a postos de trabalho. De acordo com o documento examinado, "propor a empregabilidade como princípio constitutivo quer dizer, portanto, que os estudantes, ao concluírem o ensino médio, contarão, também, com melhores condições para concorrer a postos de trabalho" (MINAS GERAIS, 2011, p. 8).

\footnotetext{
Na proposta curricular de Minas Gerais, implementada entre os anos de 2010 e 2014, o estudante optava por determinados percursos curriculares, integrados à formação básica, que buscavam uma maior aproximação ao mercado de trabalho. Tais percursos eram nomeados como "áreas de empregabilidade". Constituíamse como eixos do curso disciplinas como: Empreendedorismo e Gestão, Tecnologia da Informação, Meio ambiente e recursos naturais, Comunicação Aplicada e Turismo.
} 
A proposta curricular para o Ensino Médio deste Estado trazia como meta pedagógica

a criação de um ciclo de estudos com identidade própria, que propicie, simultaneamente, melhores condições para o prosseguimento dos estudos e mais instrumentos favorecedores da empregabilidade dos estudantes ao final de sua formação nesta etapa de ensino (MINAS GERAIS, 2011, p. 11).

Constatamos, assim, uma preocupação com a ressignificação da escola pública, de forma que atribua evidência ao estudante, enquanto protagonista de sua formação, à diversificação dos percursos formativos e ao posicionamento estratégico da empregabilidade enquanto princípio curricular.

Considerando este direcionamento, a política curricular mineira para o Ensino Médio foi materializada em uma proposta que foi caracterizada "por percursos curriculares alternativos, flexibilidade, uso das novas tecnologias de ensino/aprendizagem, atividades interdisciplinares e instrumentos formativos extraescolares" (MINAS GERAIS, 2011, p. 10). Tais percursos formativos eram sistematizados em dois grandes blocos: de um lado, as áreas de empregabilidade, de outro as disciplinas escolares exigidas para os exames de larga escala.

Dessa forma, o estudante percorre, simultaneamente, dois eixos formativos inter-relacionados com identidade clara, de modo que, ao concluir o Ensino Médio como uma etapa significativa da vida escolar, além da formação que lhe permite o prosseguimento dos estudos, conte, também, com os instrumentos proporcionados pela área de empregabilidade cursada (MINAS GERAIS, 2011, p. 10).

As nomeadas áreas de empregabilidade, assim sendo, mobilizavam-se através da flexibilização enquanto estratégia de ação. Sua prioridade estava em "incentivar a participação ativa dos nossos alunos estimulando-os a ser protagonistas da ação educativa" (MINAS GERAIS, 2011, p. 23). Os indivíduos, marcadamente os jovens contemporâneos, eram interpelados a ampliar seu repertório de habilidades, favorecendo sua inserção no mundo do trabalho, a continuidade dos estudos e a construção de possibilidade de empregabilidade. O jovem protagonista aqui delineado, com perfil formativo inovador, é capaz de ampliar seu potencial de empregabilidade através do investimento em variadas modalidades de aprendizagem permanente. A individualização, enquanto um princípio de diferenciação curricular na proposta aqui analisada, está centrada 
na formação de jovens protagonistas, responsabilizados pela ampliação de seu potencial de empregabilidade.

\subsection{As competências socioemocionais como alavancas de aprendizagem}

Através de uma parceria entre a Secretaria de Estado da Educação do Rio de Janeiro e o Instituto Ayrton Senna (IAS), foi desenvolvido, a partir do ano de 2012, o projeto curricular Solução Educacional para o Ensino Médio. Além de criar condições para qualificar a escolarização juvenil promovida naquele contexto estadual, a referida proposta assumia como compromisso

criar oportunidades educativas que favoreçam a esse jovem as competências, atitudes e valores considerados, hoje, indispensáveis ao trabalho, ao convívio, ao aprendizado permanente, à participação nas questões que afetam sua vida e a sociedade, levando-o, sobretudo, a desenvolver a autonomia necessária à realização de projetos de vida (IAS, 2012a, p. 7).

A busca por novas oportunidades educacionais para o Ensino Médio, conforme os documentos orientadores da reforma, associa-se aos investimentos realizados pelo governo estadual, em gestão educacional e na busca de formas educacionais centradas na educação integral, especialmente o programa Dupla Escola.

De acordo com os indicativos de gestão, derivados das concepções promovidas pelo Instituto Ayrton Senna, o projeto Solução Educacional para o Ensino Médio aposta em um modelo de desenvolvimento curricular centrado nas dimensões do trabalho, do convívio e da aprendizagem ao longo da vida (IAS, 2012a). A ênfase na organização do currículo supõe a disposição em áreas do conhecimento, assim como o engendramento de projetos de pesquisa e de intervenção social, ancorados na "matriz de competências para o século 21", "a ser desenvolvida por todos na escola e em todas as oportunidades educativas" (IAS, 2012a, p. 9). Seus princípios orientadores, abaixo elencados, comprometem-se com a "experimentação de novas práticas de ensino e aprendizagem" relacionadas a variados aspectos.

* ao protagonismo juvenil;

* à capacitação da equipe escolar por meio da formalização de espaços de aprendizagem e colaboração entre os educadores;

* à construção de sentido à educação, reunindo a comunidade escolar em torno de princípios, conceitos e práticas comuns; 


\begin{abstract}
* ao uso das tecnologias digitais, assim como da leitura e escrita, como dispositivos integradores no núcleo e nas áreas de conhecimento; * à abordagem de questões contemporâneas, trazendo atualidade e contextualização à aprendizagem;

* e à construção da autogestão e dos projetos de vida dos estudantes em todas as oportunidades educativas (IAS, 2012a, p. 11).
\end{abstract}

Em torno dos aspectos acima elencados, o projeto examinado fundamenta-se nos pressupostos da "educação para o século 21", intensamente promovida pelo IAS. Tais pressupostos, a partir de uma matriz holística, requerem "o desenvolvimento de um conjunto de competências necessárias para aprender, viver, conviver e trabalhar em um mundo cada vez mais complexo" (IAS, 2012b, p. 4). O foco pedagógico é direcionado para o indivíduo e suas possibilidades de aprendizagem, assegurando que os jovens "sejam capazes de solucionar problemas de maneira colaborativa, pensar criticamente e fazer escolhas responsáveis" (p. 4). Através da "Educação para o século 21", a proposta colocada em análise assume como tarefa ampliar as fronteiras da noção de aprendizagem, ancorando-se em novos paradigmas educacionais.

Sua opção pedagógica coaduna-se aos modelos de desenvolvimento humano, desenvolvidos pelo Programa das Nações Unidas para o Desenvolvimento (PNUD) nos anos 1990, procurando justapor as dimensões cognitiva e socioemocional da aprendizagem dos estudantes. Segundo esses modelos, de modo geral, as pessoas são colocadas como centro do processo de desenvolvimento, dimensionando a educação "como oportunidade central para prepará-las para fazer escolhas e transformar em competências o potencial que trazem consigo" (IAS, 2012b, p. 5). As propostas curriculares centradas nesse modelo atribuem centralidade para os aspectos socioemocionais, compreendidos enquanto "alavancas de aprendizagem", especialmente para contextos como o brasileiro. Conforme o documento examinado, são variados os sistemas conceituais mobilizados para justificar a centralidade das competências socioemocionais, advindos de áreas como a psicologia, as neurociências e a economia. Sob tais argumentos, "o desempenho cognitivo dos alunos é beneficiado quando esse grupo decisivo de competências é acionado e desenvolvido de forma intencional" (p. 6).

A opção pelas competências socioemocionais, enquanto alavancas de aprendizagem, tem sido uma estratégia central nas experiências assessoradas pelo Instituto Ayrton Senna. A justaposição de competências cognitivas e socioemocionais, permite a seleção de alguns aspectos a serem priorizados, dentre os quais destacam-se "responsabilidade, colaboração, comunicação, criatividade, 
autocontrole, pensamento crítico, resolução de problemas e abertura" (IAS, 2012b, p. 8). No âmbito do programa Solução Educacional para o Ensino Médio, particularmente, é proposto

ensinar os conteúdos curriculares a partir de uma matriz de competências para o século 21 , flexível e customizável a partir de diferentes modelos de escola - que combina competências cognitivas - como a resolução de problemas e o pensamento crítico - com competências socioemocionais - como a colaboração e a responsabilidade (IAS, 2012b, p. 13).

A Matriz de competências para o século 21 e a Gestão Integrada, derivadas dos pressupostos orientadores do programa do Instituto Ayrton Senna, tornam-se os princípios de organização dos currículos escolares para o Ensino Médio, no contexto examinado. A Figura explicita os pressupostos básicos que estruturam a referida matriz de competências.

A matriz, acima evidenciada, permite-nos visualizar, através da disposição gráfica, a articulação entre as dimensões cognitiva e socioemocional das competências. Entretanto, cumpre enaltecer que sua operacionalização ocorre através de

\section{MATRIZ DE COMPETÊNCIAS PARA O SÉCULO XXI}

$\begin{aligned} & \text { AUTOCONHECIMENTO } \\ & \text { Capacidade de usar o conhecimento de si, } \\ & \text { a estabilidade emocional e a capacidade de } \\ & \text { interagir nas tomadas de decisão, em especial } \\ & \text { em situaçöes de estresse, críticas } \\ & \text { ou provocações. }\end{aligned}$
$\begin{aligned} & \text { CoLABORAÇÃo } \\ & \text { Capacidade de atuar em sinergia } \\ & \text { responsabilidade compartilhada, respeitando } \\ & \text { diferenças e decisões comuns, adaptando-se a } \\ & \text { situaçôes sociais variadas. }\end{aligned}$

Fonte: Solução Educacional para o Ensino Médio (IAS, 2012b).

Figura. Matriz de competências para o século 21 (2012). 
um modelo de gestão integrada que aproxima a gestão do conhecimento dos modelos de avaliação de larga escala. A gestão integrada, de acordo com o documento orientador da proposta curricular para o Ensino Médio, "promove o comprometimento individual e a responsabilidade coletiva, articulando o empenho e desempenho de todos em favor do ensino e da aprendizagem, num ciclo contínuo de diagnóstico, planejamento, execução, avaliação, replanejamento e apropriação dos resultados" (IAS, 2012a, p 15). Ao operar no plano subjetivo, a individualização apresentada nessa proposta, de acordo com nossa análise, associa-se ao desenvolvimento de competências socioemocionais e sua posterior avaliação, por meio de larga escala.

\section{As comunidades de aprendentes e a centralidade das práticas investigativas}

A terceira proposta curricular para o Ensino Médio, que acompanha o regime de implementação, foi a proposta Ensino Médio Politécnico, mobilizada no estado do Rio Grande do Sul, no período entre 2011 e 2014. Diferentemente das propostas anteriormente apresentadas, na política sul-rio-grandense, a individualização das práticas curriculares situou-se no âmbito da promoção de pesquisas sobre temáticas escolhidas pelos estudantes e sistematizadas na forma de seminários integrados. Considerando o baixo desempenho das instituições locais nas avaliações nacionais, bem como o estágio de sua contribuição para o desenvolvimento econômico, o governo estadual lançou mão de pressupostos pedagógicos progressivistas para delinear a proposta de reforma que descreveremos a partir deste momento. Tais pressupostos progressivistas, com maior ou menor intensidade, atribuem uma preocupação social mais consolidada na composição curricular desta proposta.

Além da ampliação da carga horária anual desta etapa da Educação Básica, o Ensino Médio Politécnico assentava-se em determinados princípios que atribuíam centralidade às modificações que estavam em curso no mundo do trabalho, nas quais

a capacidade de fazer passa a ser substituída pela intelectualização das competências, que demanda raciocínio lógico formal, domínio das formas de comunicação, flexibilidade para mudar, capacidade de aprender permanentemente e resistência ao estresse (RIO GRANDE DO SUL, 2011, p. 13 [grifos nossos]).

A nomeada intelectualização das competências era invocada pela necessidade de a instituição escolar acompanhar as novas dinâmicas emergentes do campo tecnocientífico e, ao mesmo tempo, sintonizar-se com as novas competências 
exigidas pelo capitalismo contemporâneo. A proposta definia o domínio de determinadas ferramentas intelectuais que conduzissem os estudantes gaúchos à resolução de problemas, visto que "novos problemas surgem cotidianamente ao tempo em que conhecimentos e ocupações vão-se tornando obsoletos" (RIO GRANDE DO SUL, 2011, p. 12).

A referida proposta curricular atribuía ênfase ao conceito de "politecnia", clássica noção advinda do progressivismo pedagógico, compreendendo-o como um eixo articulador das relações entre formação geral (disciplinas escolares) e a formação profissional (demandas advindas do mundo da economia). No interior desta política, por variados sistemas de raciocínio pedagógico, também encontramos modificações nas formas de selecionar e organizar os conhecimentos a serem selecionados (GABRIEL; SILVA, 2015). A definição de currículo orientadora da proposta situava-o como "o conjunto das capacidades de todos" (RIO GRANDE DO SUL, 2011, p. 16). O desenvolvimento curricular aqui idealizado situava-se na interface entre a promoção de oportunidades e a mobilização de capacidades, e disso deriva, em nosso entendimento, a centralidade da noção de comunidades de aprendentes.

Azevedo e Reis (2013), em uma sistematização dos pressupostos orientadores da reforma, definiram que seu desafio estava em superar os arranjos escolares que se centravam na reprodução de conhecimentos descontextualizados e em avaliações classificatórias. De acordo com os autores, em visível diálogo com os paradigmas econômicos contemporâneos, deveríamos combater as formas tradicionais de planejar a escolarização juvenil, na medida em que se tratava de "um padrão curricular que tende a robotizar as mentes, reduzindo-as a formas homogêneas, a conformação com os supostos 'destinos', ao ajustamento dos pensamentos na lógica da obediência, da não proposição, da não formação de pensamento próprio [...]" (AZEVEDO; REIS, 2013, p. 29).

A partir das justificativas descritas acima, a principal inovação curricular advinda do Ensino Médio Politécnico trata do engendramento de um espaço de articulação curricular nomeado como "seminário integrado". Os referidos seminários integravam a carga horária da parte diversificada, em progressão no decorrer dos três anos da etapa da educação básica, e apresentavam-se como "espaços de comunicação, socialização, planejamento e avaliação de vivências e práticas do curso" (RIO GRANDE DO SUL, 2011, p. 26). Nestes espaços de integração curricular os estudantes deveriam desenvolver estágios, vivências e, principalmente, pesquisas. Cada turma teria um professor responsável para acompanhar e coordenar as pesquisas conduzidas por cada um dos estudantes, favorecendo a que se constituíssem as nomeadas "comunidades de aprendentes". 
Cabe ainda explicitar que, no âmbito do Ensino Médio Politécnico, os Seminários Integrados eram posicionados enquanto espaços de diálogo e de pesquisa, envolvendo os temas selecionados pelos próprios estudantes. Do ponto de vista metodológico, adquiriam evidência as estratégias problematizadoras, com foco em projetos a serem conduzidos "a partir de pesquisa que explicite uma necessidade e/ou uma situação-problema dentro dos eixos temáticos transversais" (RIO GRANDE DO SUL, 2011, p. 26 [grifos nossos]). Ao examinarmos seu documento orientador, assumia-se como objetivo político a formação de jovens protagonistas, através da pesquisa enquanto princípio curricular.

Tal como as reformas anteriormente examinadas, no Politécnico também observamos a proliferação de dispositivos curriculares centrados na individualização. Sua estratégia privilegiada - a pesquisa enquanto princípio pedagógico - interpelava aos estudantes a buscarem aprendizagens vitalícias, fazendo-se protagonistas de seu próprio percurso formativo. A comunidade de aprendentes, em termos curriculares, operava enquanto princípio e enquanto método, mobilizando a promoção de novos percursos formativos, mais sintonizados com a economia do conhecimento e com o indivíduo que ela espera formar.

\section{Considerações finais}

Por que a individualização das políticas curriculares precisa ser investigada com maior atenção? Que sentidos políticos, culturais e econômicos podem ser derivados das políticas de escolarização juvenil mobilizados hodiernamente? Recorrendo mais uma vez a Beck (2010), podemos afirmar que a individualização, de forma paradoxal, pode desonerar o indivíduo de sua condição de vida ou de seus vínculos tradicionais. Todavia, outras instituições tendem a adquirir força na medida em que "imprimem sua marca na trajetória do indivíduo e atuam no sentido contrário do arbítrio individual que se realiza sob a forma de consciência, tornando-o um joguete de modas, circunstâncias, conjunturas e mercados" (BECK, 2010, p. 194). Acompanhando a análise proposta por Beck (2010), a individualização tende a bloquear as possibilidades de uma "existência individual emancipada", pois significa uma "dependência do mercado em todas as dimensões da conduta na vida" (p. 195). Em outras palavras, poderíamos concluir que a individualização intensifica novos modos de padronização da vida.

Na medida em que a sociedade contemporânea se individualiza, como assinalamos nas seções anteriores, é importante salientar que "a biografia socialmente predeterminada é transformada em biografia feita e a ser feita por cada um" (BECK, 2010, p. 199). O indivíduo é interpelado a aprender a reconhecer-se como o centro de sua própria ação, agenciando seus percursos. Em seu diagnóstico, o 
sociólogo ainda adverte que "com base nessas pressões por autoconfiguração, autoplanejamento e autoprodução, acabarão surgindo cedo ou tarde novas demandas educacionais, tutelares, terapêuticas e políticas" (BECK, 2010, p. 200). Na educação, por exemplo, intensifica-se a promoção de currículos customizáveis, moduláveis e flexíveis às demandas, necessidades e interesses dos indivíduos (SCHERER, 2015; SILVA, 2016b).

Para concluir este artigo, apontamos que a diferenciação curricular das políticas para o Ensino Médio, no Brasil, é regulada por determinados dispositivos de individualização. Derivam de nossas análises realizadas em três Estados de nosso país, a emergência das áreas de empregabilidade, das comunidades de aprendentes e das competências socioemocionais enquanto orientadores das políticas curriculares. $\mathrm{O}$ atendimento aos interesses juvenis, a preocupação com as demandas do mundo da economia ou mesmo a redução da aprendizagem a elemento calculável são algumas condições deste cenário que se complexifica com as recentes reformas do Ensino Médio e com a construção da Base Nacional Comum Curricular. Todavia, importa assinalar que seguiremos direcionando nossa preocupação analítica para as políticas curriculares para o Ensino Médio e, particularmente, para os novos dispositivos de individualização dos percursos formativos. 


\title{
Individualizing formative paths as an organizing principle for upper secondary education curricular policies in Brazil
}

\begin{abstract}
This paper aims to examine how individualization of formative paths is positioned as an organizing principle for upper secondary education curricular policies in Brazil across this decade. By working in the Curriculum Studies, it describes and analyzes how young schooling comes to be rescaled into different "individualizing outbreaks", heightened in the conditions of "economizing the social life" and visibilizing contradictions of a "state crisis". It analyzes curricular policies in the states of Rio Grande do Sul, Minas Gerais and Rio de Janeiro.

Keywords: Curricular policies. Upper secondary education. Individualization. Brazil.

\section{La individualización de los itinerarios formativos como principio organizador de las políticas curriculares para la Enseñanza Secundaria en Brasil}

\section{Resumen}

El presente artículo se propone examinar los modos en que la individualización de los itinerarios formativos se sitúa como un principio organizador de las políticas curriculares para la enseñanza secundaria implementadas en Brasil a lo largo de esta década. Al inscribirse en el campo de los Estudios Curriculares, describe y analiza cómo la escolarización juvenil pasa a ser redimensionada en el ámbito de diferentes "brotes individualizadores", intensificados en las condiciones de una "economía de la vida social" y de la visibilización de las paradojas de una "crisis del Estado". Se realiza un análisis de políticas curriculares movilizadas en los estados de Rio Grande do Sul, Minas Gerais y Río de Janeiro.

Palabras clave: Políticas curriculares. Enseñanza Secundaria superior. Individualización. Brasil. 


\section{Referências}

AZEVEDO, J.; REIS, J. Democratização do ensino médio: a reestruturação curricular no RS. In: . (Orgs.). Reestruturação do ensino médio. São Paulo: Fundação Santillana, 2013. p. 21-44.

BALIBAR, E. Los dilemas históricos de la democracia y su relevancia contemporánea para la ciudadanía. Enrahonar: Quaderns de Filosofia, v. 48, p. 9-29, 2012.

BALL, S. Gobernanza neoliberal y democracia patológica. In: COLLET, J.; TORT, A. (Orgs.). La gobernanza escolar democrática. Madrid: Morata, 2016. p. 23-40.

BAUMAN, Z. Estado de crise. Rio de Janeiro: Zahar, 2016.

BECK, U. Sociedade de risco: rumo a uma outra modernidade. São Paulo: Editora 34, 2010.

CLAPARÈDE, E. A escola sob medida. Rio de Janeiro: Fundo de Cultura, 1973.

DARDOT, P.; LAVAL, C. A nova razão do mundo: ensaio sobre a sociedade neoliberal. São Paulo: Boitempo, 2016.

FAWTHROP, J. Developing group work skills. HART, S. (Org.).

Differentiation and the secondary curriculum: debates and dillemmas. New York: Routledge, 1996. p. 64-78.

FIELDING, M. Why and how learning styles matter: valuing difference in teachers and learners. In: HART, S. (Org.). Differentiation and the secondary curriculum: debates and dillemmas. New York: Routledge, 1996. p. 81-103.

FUMAGALLI, A. O conceito de subsunção do trabalho ao capital: rumo à subsunção da vida no capitalismo cognitivo. Cadernos IHU Ideias, v. 14, n. 246, p. 1-22, 2016.

GABRIEL, C.; SILVA, R. Políticas curriculares para o Ensino Médio no Brasil: o conhecimento escolar entre duas lógicas. In: PEREIRA, M.; ALBINO, A.; DANTAS, V. (Orgs.). Políticas de currículo e formação. João Pessoa: Editora da UFPB, 2015. p. 70-90.

HART, S. Differentiation and equal opportunities. In: HART, S. (Org.). Differentiation and the secondary curriculum: debates and dillemmas. New York: Routledge, 1996. p. 9-25. 
INSTITUTO AYRTON SENNA - IAS. Competências socioemocionais: material para discussão. Rio de Janeiro, 2012b.

. Solução educacional para o Ensino Médio. Rio de Janeiro, 2012a.

JESSOP, B. ¿Narrando el futuro de la Economía Nacional y el Estado Nacional? Puntos a considerar acerca del replanteo de la regulación y la re-invención de la gobernancia. Documentos y Aportes en Administración Pública yGestión Estatal, n. 7, p. 7-44, 2006.

KRAWCZYK, N. Reflexão sobre alguns desafios do ensino médio no Brasil hoje. Cadernos de Pesquisa, v. 41, n. 144, p. 752-69, set./dez. 2011. https:// doi.org/10.1590/S0100-15742011000300006

LAVAL, C. La escuela no es una empresa. Barcelona: Paidós, 2004.

MINAS GERAIS. Secretaria da Educação. Reinventando o Ensino Médio. Belo Horizonte, 2011.

NOBILE, M. Los egresados de las escuelas de reingreso: sobre los soportes mínimos para aprovechar una política de reinserción educativa. Espacios en Blanco, n. 26, p. 187-210, 2016.

PACHECO, J. Educação, formação e conhecimento. Porto: Porto, 2014.

PERRENOUD, P. Pedagogia diferenciada. Porto Alegre: Artmed, 2000.

PETERS, M. Economias biopolíticas da dívida. Cadernos IHU Ideias, v. 14, n. 236, p. 1-16, 2016.

RIO GRANDE DO SUL. Secretaria da Educação. Proposta pedagógica para o ensino médio politécnico. Porto Alegre, 2011.

SCHERER, R. "Cada um aprende de um jeito": das adaptações às flexibilizações curriculares. 2015. 173 f. Dissertação (Mestrado em Educação) —Unisinos, São Leopoldo, RS, 2015.

SILVA, M. R.; JAKIMIU, V. C. L. Do texto ao contexto: o Programa Ensino Médio Inovador em movimento. Ensaio: Avaliação e Políticas Públicas em Educação, v. 24, n. 93, p. 910-38, dez. 2016. http://dx.doi.org/10.1590/ S0104-40362016000400007

SILVA, R. Currículo e conhecimento escolar na sociedade das capacitações: o ensino médio em perspectiva. Revista E-curriculum, v. 14, n. 2, p. 676-67, 2016 b. 
SILVA, R. Investir, inovar e empreender: uma nova gramática curricular para o ensino médio brasileiro. Currículo sem Fronteiras, v. 16, n. 2, p. 178-96, $2016 \mathrm{a}$.

SOUSA, F. Diferenciação curricular e deliberação docente. Porto: Porto, 2010.

TIRAMONTI, G.. Escuela media: la identidad forzada. In: TIRAMONTI, G.

(Org.). Variaciones sobre la forma escolar. Buenos Aires: Flacso, 2014. p. 17-33.

\section{Informações do autor}

Roberto Rafael Dias da Silva: Doutor em Educação. Professor do Programa de PósGraduação em Educação da Universidade do Vale do Rio dos Sinos (UNISINOS). Contato: robertods@unisinos.br

(iD) http://orcid.org/0000-0001-6927-3435 